\title{
Lysinuric Protein Intolerance
}

\author{
BASOLATERAL TRANSPORT DEFECT IN RENAL TUBULI
}

\author{
J. Rajantie, O. Simell, and J. Perheentupa, Children's Hospital, University of \\ Helsinki, 00290 Helsinki 29, Finland
}

A B S T R A C T In patients with an autosomal recessive diamino acid transport disorder, lysinuric protein intolerance (LPI), we measured plasma and urinary amino acids basally, and during intravenous infusion of citrulline at two rates. Compared with controls, the patients' plasma citrulline concentrations rose similarly, but urinary citrulline excretion increased excessively. Their plasma arginine and ornithine levels rose subnormally, but massive argininuria and moderate ornithinuria appeared. The excretion rates of the third diamino acid lysine and other amino acids remained practically unaltered, thus excluding mutual competition as the cause for the increases. The results suggest that $(a)$ in the normal kidney reabsorption involves partial conversion of citrulline to arginine and ornithine (metabolic run-out), (b) in LPI, the diamino acid transport defect is located at the basolateral cell membrane of the renal tubules; this inhibits the efflux of arginine and ornithine, increasing their cellular concentration, which in turn inhibits the metabolic disposal of citrulline, and causes leakage of arginine, ornithine, and citrulline into the tubular lumen.

\section{INTRODUCTION}

Lysinuric protein intolerance $(\mathrm{LPI})^{1}$ is an autosomal recessive disease due to a defect in the transport of the diamino acids lysine, arginine, and ornithine by the intestinal mucosa (1) and renal tubuli (2) and, according to indirect evidence, the hepatocytes $(3,4)$. Large amounts of the diamino acids are lost in the urine and their concentrations in plasma are decreased. A consequence of this defect is hyperammonemia after protein intake. The hyperammonemia can be prevented by supplementing the protein with arginine (5), ornithine $(6)$, or citrulline $(7,8)$. The conclusion has been drawn that the hyperammonemia is due to a hepa-

Received for publication 19 February 1980 and in revised form 12 November 1980.

${ }^{1}$ Abbreviation used in this paper: LPI, lysinuric protein intolerance. tic functional deficiency of the urea cycle intermediates ornithine and arginine, resulting in impaired function of the cycle (5). The defect in the intestinal mucosal cells is probably in the efflux mechanisms at the basolateral membrane $(9,10)$. The neutral amino acid citrulline, in contrast to the diamino acids, is absorbed normally from the intestine (1).

We have now studied the renal handling of citrulline in patients with LPI during standardized intravenous infusions of citrulline. Our findings suggest that, during tubular reclamation, part of the citrulline is converted into arginine and ornithine (metabolic run-out) (11) and that in LPI the basolateral efflux mechanism of the diamino acids is defective in the renal tubular cells as in the intestinal epithelium.

\section{METHODS}

Three patients with LPI were studied: patient 1 , male, $34 \mathrm{yr}$, $73 \mathrm{~kg}$; patient 2 , female, $26 \mathrm{yr}, 35 \mathrm{~kg}$; patient 3 , female, 12 yr, $30 \mathrm{~kg}$. All had a history typical of LPI (5). They were compared with two healthy female volunteers: control $1,19 \mathrm{yr}$, $55 \mathrm{~kg}$; control $2,31 \mathrm{yr}, 51 \mathrm{~kg}$. All subjects and/or their guardians had given informed consent to the studies. The patients were on a diet with normal caloric and low to normal protein content supplemented with $0.5 \mathrm{mmol}$ of citrulline for each gram of protein (8). This supplementation was interrupted at least $24 \mathrm{~h}$ before the studies. The tests were started in the morning after a 10-h fast. During the tests the subjects were allowed only water; they all remained symptom free. Urinary creatinine clearance was measured for every subject, and was found to be normal

Intravenous infusion of citrulline at stepwise increasing rates. An infusion of $5 \%(\mathrm{wt} / \mathrm{vol})$ mannitol solution with 20 $\mathrm{mM} \mathrm{NaCl}$ and $15 \mathrm{mM} \mathrm{KCl}$ was given at $10 \mathrm{ml} / \mathrm{kg}$ of body mass/h. The citrulline concentration was increased at 2-h intervals to give consecutive infusion rates of 0,27 , and 54 $\mu \mathrm{mol} / \mathrm{kg}$ per $30 \mathrm{~min}$. A priming dose, $31.5 \mu \mathrm{mol}$ citrulline $/ \mathrm{kg}$ as a $5 \%$ aqueous solution, preceded each increase. Venous plasma was obtained before citrulline administration and at 60,90 , and $120 \mathrm{~min}$ after each priming. The mean variation (for patients and controls together) in plasma concentration of citrulline was $6.0 \%$, calculated as $100 \cdot(\mathrm{III}-\mathrm{I}) /(\mathrm{III}+\mathrm{I})$, where I and III refer to concentrations in the 60 and $120-\mathrm{min}$ samples. A steady-state concentration of citrulline in plasma was thus assumed to prevail between 60 and $120 \mathrm{~min}$ after the primings and the mean concentration for each period was 
TABLE I

Effect of Two Rates of Intravenous Citrulline Infusion in Controls and Patients with LPI on Urinary Excretion of Citrulline and the Diamino Acids

\begin{tabular}{lllll}
\hline $\begin{array}{c}\text { Rate of citrulline } \\
\text { infusion* }\end{array}$ & \multicolumn{1}{c}{ Citrulline* } & Arginine* & Ornithine & Lysine $^{*}$ \\
\hline $\begin{array}{c}\text { Controls } \\
0\end{array}$ & & & & \\
27 & $0.00,0.00$ & $0.00,0.01$ & $0.02,0.02$ & $0.05,0.13$ \\
54 & $0.00,0.00$ & $0.00,0.01$ & $0.10,0.09$ & $0.10,0.11$ \\
& $0.05,0.10$ & $0.06,0.04$ & $0.23,0.19$ & $0.12,0.15$ \\
Patients with LPI & & & & \\
0 & $0.04,0.11,0.06$ & $0.16,0.25,0.17$ & $0.10,0.07,0.05$ & $2.72,5.33,4.07$ \\
27 & $0.23,0.89,0.43$ & $1.04,3.30,1.17$ & $0.53,0.70,0.27$ & $2.42,5.41,3.60$ \\
54 & $1.08,1.19,1.45$ & $2.67,6.21,3.23$ & $1.14,1.20,0.76$ & $2.84,3.36,3.26$ \\
\hline
\end{tabular}

* All values are in micromoles per kilogram per $30 \mathrm{~min}$. All results are means of values obtained for two consecutive collection periods. The first figure is for control 1 or patient 1 , etc.

used for calculations. A 30- or 60-min urine collection preceded the first priming, for measurement of basal excretion. During each infusion period, between 60 and $\sim 120 \mathrm{~min}$, two accurately timed (25-35 min) urines were collected by voiding. The mean variation (for patients and controls together) between the two periods in the urinary citrulline excretion rate (micromoles per kilogram per $30 \mathrm{~min}$ ) was $13.6 \%$, calculated as $100 \cdot(\mathrm{II}-\mathrm{I}) /(\mathrm{II}+\mathrm{I})$, where I and II refer to rates in the two periods.

The plasma samples were deproteinized with $50 \%$ (wt/vol) sulfosalicylic acid and stored, like the urines, at $-23^{\circ} \mathrm{C}$. Amino acids were analyzed with an automatic amino acid analyzer (Beckman $121 \mathrm{M}$, Beckman Instruments, Inc., Fullerton, Calif.) with norleucine as internal standard. Creatinine was measured by a modified Jaffe reaction (12) in all urines, and in serum samples taken basally, and at $90 \mathrm{~min}$ during each steady state.

Student's $t$ test was used throughout.

\section{RESULTS}

During fasting, the plasma citrulline concentrations were 12.0 and $14.3 \mu \mathrm{M}$ in the two controls and 83.8, 34.4 , and $18.5 \mu \mathrm{M}$ in the three patients, the plasma arginine concentration 23.0 and $66.3 \mu \mathrm{M}$, and 26.5, 21.1, and $16.3 \mu \mathrm{M}$, and the plasma ornithine concentrations 27.0 and $40.7 \mu \mathrm{M}$ and $20.5,4.8$, and $6.0 \mu \mathrm{M}$, respectively. Basal urinary excretion rates in both groups of subjects (Table I) were in good agreement with previous findings $(2,13)$.

Citrulline infusions. At both rates of citrulline infusion, the steady-state plasma citrulline concentrations were almost the same in two of the three patients and in the controls. But in patient 1 the concentrations were approximately twice as high (Fig. 1).

In contrast, the plasma arginine in the patients remained below the mean level of the controls by 60-75\%. Plasma ornithine concentrations showed smaller differences, 21-68\%. There was a clear difference between patients and controls in the steepness of the rise in plasma arginine, but not in plasma ornithine.
During elevated steady-state concentrations of citrulline, the urinary excretion of this neutral amino acid was greatly increased in every patient, in contrast to the controls (Table I). Though patient 1 had $100 \%$ higher plasma levels, his urinary excretion rates were the lowest in the group. Even more impressive, as compared with the small effect in the controls, was the massive increase in the patients' excretion of arginine. In ornithine excretion the difference from the controls was less striking; the increase in the patients was much smaller than for arginine, while in the controls there was a clearer increase in ornithine than in arginine excretion. The sum of the excretion rates of citrulline,

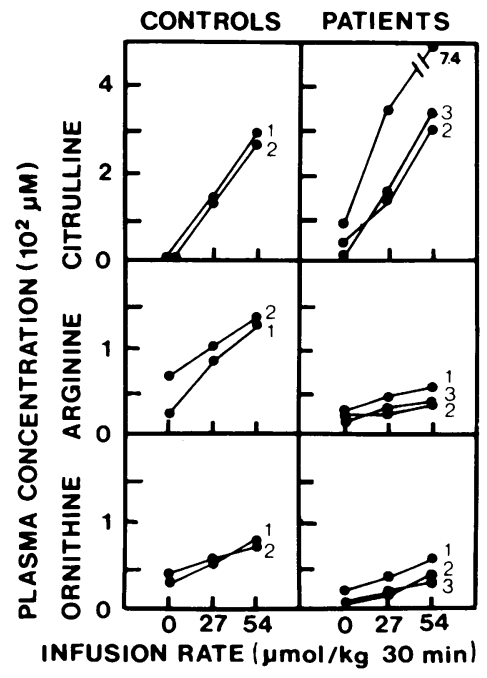

FIgURE 1 Plasma concentrations of citrulline, arginine, and ornithine at steady states in controls and patients with LPI before and during intravenous infusion of citrulline. The infusion rate of citrulline was increased stepwise at 2-h intervals from 0 to 27 and then to $54 \mu \mathrm{mol} / \mathrm{kg}$ per $30 \mathrm{~min}$. Each step was preceded by a priming dose. The curves of individual subjects are identified with numbers. 
arginine, and ornithine, as a percentage of the citrulline infusion rate, was $<0.7 \%$ in the controls and $7-20 \%$ (mean $11 \%$ ) in the patients.

In clear contrast to the other diamino acids there were no increases in the excretion of lysine. The plasma concentrations and excretion rates of all other amino acids remained practically unaltered. The summed rates of excretion of 13 neutral amino acids (excluding citrulline) for the three patients were $4.3,3.7$, and 4.3 $\mathrm{mmol} / \mathrm{kg}$ per $30 \mathrm{~min}$ basally, and $3.0,2.3$, and $4.8 \mathrm{mmol} /$ $\mathrm{kg}$ per $30 \mathrm{~min}$, respectively, during the higher rate of infusion. Of the patients' increments in urinary excretion, in the mean only $1.6 \%$ of the arginine and $20.8 \%$ of the ornithine was calculated to be due to the increase in the corresponding plasma concentrations (Table II). The remainders of the increments appear to have been due to leakage from the tubular cells of these metabolites of citrulline, which itself was filtered and reabsorbed into these cells in large amounts because of the high plasma levels produced by the infusions. Assuming that the glomerular filtration rate equalled the creatinine clearance, which was measured for each collection period, $5-40 \%$ (mean $13 \%$ ) of the filtered citrul- line was estimated to have been excreted as arginine, and $1.5-6.4 \%$ (mean $2.6 \%$ ) as ornithine.

\section{DISCUSSION}

Our present main findings in patients with LPI, after induced elevations of plasma citrulline, were: $(a)$ abnormally large citrullinuria with $(b)$ a massive increase in argininuria and moderate increase in ornithinuria, and $(c)$ no such change in the excretion of the third diamino acid lysine or of the other amino acids. We have previously produced evidence that in the intestinal mucosa the transport defect is located at the basolateral cell membrane $(9,10)$. Are our present observations consistent with the presence of the same defect at the basolateral membrane of the renal proximal tubular cells? Our findings clearly establish citrullinuria as a characteristic of LPI, especially during elevated plasma citrulline levels: at identical plasma citrulline levels, patients with LPI excreted citrulline at 10 to 50 -fold rates as compared with controls. Citrulline is neutral and, in contrast to the basic diamino acids, is absorbed normally from the small intestine of pa-

TABLE II

Creatinine Clearances, Estimates of Filtration Rates of Citrulline, Arginine, and Ornithine, of Increments in Excretion Rates Caused by Increased Filtration of the Amino Acid Itself, and of Increments in Excretion Rates Not So Explained during Intravenous Citrulline Infusion in Three Patients with LPI*

\begin{tabular}{|c|c|c|c|c|c|c|c|c|}
\hline \multirow{2}{*}{$\begin{array}{l}\text { Rate of } \\
\text { citrulline } \\
\text { infusion } \$\end{array}$} & \multirow[b]{2}{*}{$\mathrm{C}_{\mathrm{er}}$} & \multicolumn{3}{|c|}{ FILTt } & \multicolumn{2}{|c|}{$\Delta \mathrm{EXCR}_{\mathrm{FuLT}}$} & \multicolumn{2}{|c|}{$\triangle \mathrm{EXCR}_{\mathrm{ExCESs}} \ddagger$} \\
\hline & & CIT & ARG & ORN & ARG & ORN & ARG & ORN \\
\hline \multicolumn{9}{|l|}{ Patient 1} \\
\hline 0 & 93.4 & 7.8 & 2.5 & 1.9 & & & & \\
\hline 27 & 64.8 & 21.5 & 2.4 & 2.4 & 0.00 & 0.03 & 0.90 & 0.44 \\
\hline 54 & 70.5 & 52.3 & 3.9 & 4.3 & 0.07 & 0.12 & 2.44 & 0.92 \\
\hline \multicolumn{9}{|l|}{ Patient 2} \\
\hline 0 & 149.4 & 5.1 & 3.2 & 0.7 & & & & \\
\hline 27 & 135.8 & 19.2 & 3.7 & 2.4 & 0.04 & 0.16 & 3.00 & 0.45 \\
\hline 54 & 107.4 & 35.6 & 3.8 & 4.6 & 0.05 & 0.36 & 5.92 & 0.78 \\
\hline \multicolumn{9}{|l|}{ Patient 3} \\
\hline 0 & 114.1 & 2.1 & 1.9 & 0.7 & & & & \\
\hline 27 & 76.2 & 12.3 & 2.1 & 1.6 & 0.02 & 0.06 & 0.99 & 0.17 \\
\hline 54 & 94.9 & 30.3 & 3.3 & 3.0 & 0.13 & 0.15 & 2.95 & 0.57 \\
\hline
\end{tabular}

* Amino acid filtration rates were calculated by multiplying actual creatinine clearances $\left(\mathrm{C}_{\mathrm{cr}}\right)$ by the mean of the plasma concentration of the amino acid as measured at the beginning and end of each collection period. In calculations of excretion rates caused by increased filtration $\left(\triangle \mathrm{EXCR}_{\mathrm{FILT}}\right)$, excretion was assumed to show linear dependence on filtration (as observed in ref. 2); thus for each amino acid $\Delta \mathrm{EXCR}_{\mathrm{FILT}}=\left(\mathrm{FILT}_{\mathrm{i}} / \mathrm{FILT}_{\mathrm{b}}\right.$ $\left.\times \Delta E X C R_{b}\right)-\Delta E X C R_{b}$, where $b=$ basal, $i=$ during infusion. Increments in excretion rates not so explained $\left(\Delta \mathrm{EXCR}_{\mathrm{EXCESS}}\right)$ was obtained as $\triangle \mathrm{EXCR}-\Delta \mathrm{EXCR}_{\mathrm{FILT}}$. The contribution of filtered citrulline (CIT) to the basal excretion of arginine (ARG) and ornithine (ORN) could not be estimated, and was neglected. Hence values obtained for $\triangle E_{X X R_{F I T}}$ are overestimates. Consequently, values obtained for $\Delta \mathbf{E X C R}_{\text {ExcEss }}$ are presumably underestimates.

\$ All values are in micromoles per kilogram per $30 \mathrm{~min}$. All results are means of values obtained for two consecutive collection periods. 
tients with LPI $(1,7)$. Thus, the basolateral exit mechanism of the diamino acids, which is defective in the small intestinal mucosal cells of the patients $(9,10)$, does not seem to play a part in the absorption of citrulline. Hypercitrullinuria is not a feature of classical cystinuria. Hence, citrulline is not carried by the tubular luminal uptake mechanism shared by the diamino acids and cystine, the mechanism that is probably defective in cystinuria (14). Thus, the association of hypercitrullinuria with hyperdiaminoaciduria cannot be explained by competition between citrulline and the diamino acids for luminal uptake. On the other hand, the absence of hypercystinuria in LPI argues against a defect of at least the same luminal mechanism as in cystinuria. In contrast, the renal observations in LPI are well explained by a defect in the basolateral efflux mechanism of the diamino acids (Fig. 2). In basolateral transport, cystine does not compete with the diamino acids (15-17). Normal luminal uptake with a defective basolateral exit would lead to increased cellular concentrations of the diamino acids and to their increased leakage into the lumen. The kidneys have the ability to convert citrulline into arginine (18); further conversion into ornithine may be limited by low arginase activity (19). The presence of citrullinuria in patients with LPI suggests that this metabolic run-out of citrulline plays a role in its tubular reabsorption. If some of the absorbed citrulline is converted into ornithine and arginine, especially the latter, in the tubular cells, this will further increase the already high concentrations of these diamino acids. As a result, their luminal backflux will increase. Furthermore, accumulation of the conversion products of citrulline may inhibit its metabolic disposal and lead to cellular accumulation of citrulline as
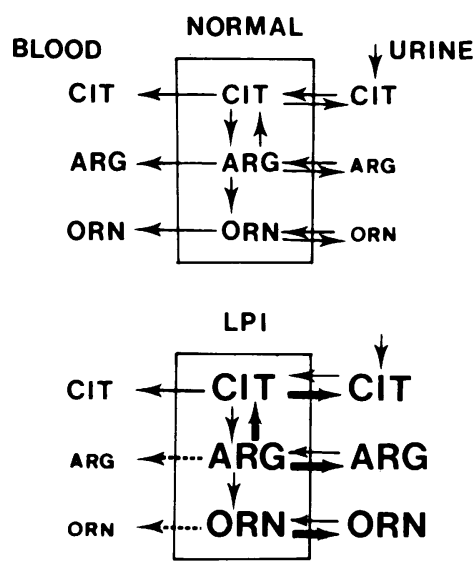

FIgURE 2 Suggested mechanism of tubular reabsorption of citrulline in man, and of pathophysiology of the massive argininuria and moderate citrullinuria and ornithinuria in LPI. Bold type and arrows indicate increased concentrations and fluxes, thin type and dotted arrows decreased concentrations and impaired fluxes. For details, see text. well, and its luminal backflux. Such metabolic disposal of reabsorbed citrulline is presumably significant even at normal or slightly elevated tubular loads, because the patients already had citrullinuria during the basal collections. Its importance appears to increase greatly with increasing tubular loads of citrulline, as judged from the steep increase in the excretion of citrulline, ornithine, and arginine, especially the latter, with increasing plasma concentrations of citrulline. On the other hand, this renal conversion of citrulline probably contributed to the rise in plasma arginine and ornithine levels in both controls and patients. Metabolic disposal is known for reabsorbed proline in the mouse kidney (20).

Citrulline has been suggested to share a tubular reabsorption mechanism with the other neutral amino acids $(15,21)$. Our present observations of unaltered excretion of other neutral amino acids during hypercitrullinuria and similar lack of association in the even more pronounced hypercitrullinuria of patients with citrullinemia (22) do not support that suggestion.

The fact that arginine excretion was greatly increased over ornithine may be due to poor cellular conversion of arginine to ornithine, but also to greater impairment of arginine transport (2). The three diamino acids lysine, arginine, and ornithine, are mutually competitive for reabsorption in the kidney tubuli both in vivo (2) and in vitro (16). In the LPI kidney, the reabsorption of lysine, arginine, and ornithine is reduced, in that descending order (2). In our present experiments lysine excretion remained unaffected by increases in the amounts of arginine and ornithine excreted. This appears to exclude a major contribution by competitive inhibition to the observed increase in argininuria and ornithinuria. Thus our observations afford indirect evidence that metabolic disposal plays a role in the reabsorption of citrulline and that the metabolic error in LPI is due to a defect in the mechanism for the basolateral efflux of the diamino acids from the tubular cells.

\section{REFERENCES}

1. Rajantie, J., O. Simell, and J. Perheentupa. 1980. Intestinal absorption in lysinuric protein intolerance: impaired for diamino acids, normal for citrulline. Gut. 21: 519-524.

2. Simell, O., and J. Perheentupa. 1974. Renal handling of diamino acids in lysinuric protein intolerance. J. Clin. Invest. 54: 9-17.

3. Simell, O., and J. Perheentupa. 1974. Defective metabolic clearance of plasma arginine and ornithine in lysinuric protein intolerance. Metab. Clin. Exp. 23: 691-701.

4. Simell, O. 1975. Diamino acid transport into granulocytes and liver slices of patients with lysinuric protein intolerance. Pediatr. Res. 9: 504-508.

5. Simell, O., J. Perheentupa, J. Rapola, J. K. Visakorpi, and L. E. Eskelin. 1975. Lysinuric protein intolerance. Am. J. Med. 59: 229-240.

6. Russel, A., M. Statter, and A. Ben-Zvi. 1977. Ornithine ad- 
ministration as a therapeutic tool in dibasic aminoaciduric protein intolerance. Hum. Hered. 27: 206.

7. Awrich, A. E., W. J. Stackhouse, J. E. Cantrell, J. H. Patterson, and D. Rudman. 1975. Hyperdibasicaminoaciduria, hyperammonemia and growth retardation: treatment with arginine, lysine, and citrulline. J. Pediatr. 87: 731-738.

8. Rajantie, J., O. Simell, and J. Perheentupa. 1980. Lysinuric protein intolerance: a two-year trial of dietary supplementation therapy with citrulline and lysine. $J$. Pediatr. 97:927-932.

9. Rajantie, J., O. Simell, and J. Perheentupa. 1980. Basolateral-membrane transport defect for lysine in lysinuric protein intolerance: Lancet. I: 1219-1221.

10. Desjeux, J-F., J. Rajantie, O. Simell, A-M. Dumontier, and J. Perheentupa. 1980. Lysine fluxes across the jejunal epithelium in lysinuric protein intolerance. J. Clin. Invest. 65: 1382-1387.

11. Scriver, C. R., R. W. Chesney, and R. R. McInnes. 1976. Genetic aspects of renal tubular transport: Diversity and topology of carriers. Kidney Int. 9: 149-171.

12. Bartels, H., M. Böhmer, and C. Heierli. 1972. Serum Kreatininbestimmung ohne Enteiweissen. Clin. Chim. Acta. 37: 193-197.

13. Kekomäki, M., J. K. Visakorpi, J. Perheentupa, and L. Saxén. 1967. Familial protein intolerance with deficient transport of basic amino acids. An analysis of 10 patients. Acta Paediatr. Scand. 56: 617-630.

14. DeFronzo, R. A., and S. O. Thier. 1978. Renal tubular defects in phosphate and amino acid transport. In Physiology of Membrane Disorders. T. E. Andreoli, J. F. Hoffman, and D. D. Fanestil, editors. Plenum Publishing Corporation, New York. 1041-1061.
15. Wilson, O. H., and C. R. Scriver. 1967. Specificity of transport of neutral and basic amino acids in rat kidney. Am.J. Physiol. 213: 185-190.

16. Rosenberg, L. E., S. J. Downing, and S. Segal. 1962. Competitive inhibition of dibasic amino acid transport in rat kidney. J. Biol. Chem. 237: 2265-2270.

17. Segal, S., L. Schwartzman, S. Blair, and D. Bertoli. 1967. Dibasic amino acid transport in rat-kidney cortex slices. Biochim. Biophys. Acta. 135: 127-135.

18. Borsook, H., and J. W. Dubnoff. 1941. The conversion of citrulline to arginine in kidney. J. Biol. Chem. 141: 717-738.

19. Szepesi, B., E. H. Avery, and R. A. Freedland. 1970. Role of kidney in gluconeogenesis and amino acid metabolism. Am. J. Phys. 219: 1627-1631.

20. Scriver, C. R., R. R. McInnes, and F. Mohyuddin. 1975. Role of epithelial architecture and intracellular metabolism in proline uptake and transtubular reclamation in PRO/Re mouse kidney. Proc. Natl. Acad. Sci. U. S. A. 72: $1531-1535$.

21. Christensen, H. N., and A. M. Cullen. 1973. Synthesis of metabolism-resistant substrates for the transport system for cationic amino acids; their stimulation of the release of insulin and glucagon and of the urinary loss of amino acids related to cystinuria. Biochim. Biophys. Acta. 298: 935-950.

22. Shih, V. E. 1978. Urea cycle disorders and other congenital hyperammonemic syndromes. In The Metabolic Basis of Inherited Disease. J. B. Stanbury, J. B. Wyngaarden, and D. S. Fredrickson, editors. McGraw-Hill Inc., New York. 362-386. 